\title{
Effect of beclin 1 expression on the biological behavior and chemotherapy sensitivity of cervical cancer cells
}

\author{
YONGXIN ZHANG ${ }^{1}$, SHUANG LIN $^{1}$, YUE ZHANG $^{1}$ and SUWEN CHANG ${ }^{2}$ \\ ${ }^{1}$ Department of Gynecology, Yantai Shan Hospital; ${ }^{2}$ Department of Gynecology, \\ Yantai Yuhuangding Hospital Affiliated to Qingdao University, Yantai, Shandong 264000, P.R. China
}

Received March 9, 2015; Accepted March 18, 2016

DOI: $10.3892 / \mathrm{ol} .2016 .4542$

\begin{abstract}
The present study aimed to evaluate the effect of the expression of the autophagic gene beclin 1 on the biological behavior and chemotherapy sensitivity towards Taxol ${ }^{\circledR}$ of cervical cancer HeLa cells. A beclin 1 expression vector was constructed and tranfected into HeLa cells. Reverse transcription-polymerase chain reaction and western blotting were used to detect the expression of beclin 1. Cell proliferation was detected based on the growth curve of the cells. The effect of beclin 1 expression on cell apoptosis was analyzed using Hoechst 33258 staining, which enabled to observe the morphology of apoptotic cells. Apoptosis-associated proteins were measured by western blot assay. The sensitivity of HeLa cells to Taxol ${ }^{\circledR}$ was analyzed by 3-(4,5-dimethylthiazol-2-yl)-2,5-diphenyltetrazolium bromide assay. Beclin 1 expression at the messenger RNA and protein levels was elevated following transfection of the beclin 1 expression plasmid $(\mathrm{P}<0.05)$. Hoechst 33258 staining revealed that the apoptosis rate of the transfected HeLa cells was significantly higher than that of normal HeLa cells. The expression of caspase- 3 was increased in the transfected cells, and beclin 1 transfection increased B-cell lymphoma 2 (Bcl-2)-associated $\mathrm{X}$ protein (Bax):Bcl-2 ratio, resulting in Bax activation and Bcl-2 suppression $(\mathrm{P}<0.05)$. Chemotherapy sensitivity analysis demonstrated that the half maximal inhibitory concentration values of Taxol ${ }^{\circledR}$ of the transfection, non-transfection and mock-vehicle groups were $30.4,118.0$ and $125.5 \mu \mathrm{g} / \mathrm{ml}$, respectively. Beclin 1 inhibited proliferation and increased apoptosis of HeLa cells, and also increased the chemosensitivity of these cells to Taxol ${ }^{\circledR}$. The present results confirmed that beclin 1 is a favorable prognostic biomarker for cervical cancer treatment, and may serve to identify particular patients for individual therapy.
\end{abstract}

Correspondence to: Dr Yongxin Zhang, Department of Gynecology, Yantai Shan Hospital, 91 Jiefang Road, Zhifu, Yantai, Shandong 264000, P.R. China

E-mail: zh_yxin@sina.com

Key words: beclin 1, cervical cancer cells, biological behavior, chemotherapy sensitivity

\section{Introduction}

Cervical cancer is a common malignant tumor of the female reproductive system, and is responsible for $\sim 250,000$ annual mortalities (1). Neoadjuvant chemotherapy is important in cervical cancer treatment, since general chemotherapy drugs may promote tumor cell death by inducing cell apoptosis, but tend to induce drug resistance (2). Autophagy is a process of self-digestion by a cell through the action of enzymes originating within its lysosome of the same cell (3). Autophagy is often induced under conditions of stress that could also lead to cell death (4-6). Abnormal regulation of autophagy is closely associated with the incidence and development of tumors; thus, autophagic cell death may be considered a novel target for cancer treatment (6).

Beclin 1 is a $60-\mathrm{kDa}$ coiled-coil protein that was identified in rats with fatal Sindbis viral encephalitis in 1998 (7). Beclin 1 is a B-cell lymphoma 2 (Bcl-2) homology 3 domain-only protein that is essential for the formation of double-membrane autophagosomes, which are required in the initial step of autophagy (7-9). Previous studies have reported that cell autophagy is closely associated with tumor initiation and progression, and is important in cell signal regulation in tumors (10-12). However, the effects of beclin 1 on the biological behavior and chemotherapy sensitivity of cervical cancer cells have not been studied in detail thus far. In the present study, a beclin 1 expression vector was constructed and transfected into human cervical cancer cells to investigate the effects of beclin 1 expression on the biological behavior and chemotherapy sensitivity of HeLa cells.

\section{Materials and methods}

Materials. The human cervical cancer cell line HeLa was obtained from the cell resource center of Shanghai Institutes for Biological Sciences of Chinese Academy of Sciences (Shanghai, China). TRIzol ${ }^{\circledR}$ and Lipofectamine ${ }^{\circledR} 2000$ were purchased from Invitrogen (Thermo Fisher Scientific, Inc., Waltham, MA, USA). Reverse transcription-polymerase chain reaction (RT-PCR) kit was purchased from Fermentas (Thermo Fisher Scientific, Inc.). Taxol ${ }^{\circledR}$ (paclitaxel injection) was purchased from Bristol-Myers Squibb (New York, NY, USA).

Cell transfection. HeLa cells were cultured in Gibco Dulbecco's modified Eagle's medium (DMEM; Thermo Fisher 
Scientific, Inc.) supplemented with $10 \%$ (v/v) heat-inactivated Gibco fetal bovine serum (Thermo Fisher Scientific, Inc.) and penicillin-streptomycin (100 IU/ml-100 $\mu \mathrm{g} / \mathrm{ml}$; Roche Applied Science, Penzberg, Germany) at $37^{\circ} \mathrm{C}$ in a humidified atmosphere of $5 \% \mathrm{CO}_{2}-95 \%$ air. Cells at logarithmic phase were seeded at a density of $3 \times 10^{5}$ cells/well in a 6 -well plate for $24 \mathrm{~h}$ prior to transfection. Beclin 1 expression plasmid was constructed as previously reported (12). Lipofectamine ${ }^{\circledR} 2000$ (4 $\mu 1$ diluted in $100 \mu \mathrm{l}$ DMEM) was used for the transfection of $0.5 \mu \mathrm{g}$ beclin 1 expression vector or empty vector diluted in $100 \mu 1 \mathrm{DMEM}$, followed by incubation of the samples for $20 \mathrm{~min}$ at room temperature. The plasmid DNA-Lipofectamine ${ }^{\circledR} 2000$ complex was then added into the cell medium, and incubated at $37^{\circ} \mathrm{C}$ in a $\mathrm{CO}_{2}$ incubator for $8 \mathrm{~h}$. Subsequently, the medium was replaced, and the cells were incubated for $48 \mathrm{~h}$ prior to be used in the corresponding experiments, which included a blank control group (non-transfected HeLa cells); a negative control group (HeLa cells transfected with mock-vehicle) and the experimental group (HeLa cells transfected with beclin 1 expression vector). Transfected cells were collected at $48 \mathrm{~h}$ post-transfection and used in the subsequent experiments.

RT-PCR for the detection of beclin 1 expression. Cells were collected at $48 \mathrm{~h}$ post-transfection, and total RNA was extracted using TRIzol ${ }^{\circledR}$ (Thermo Fisher Scientific) for the detection of beclin 1 expression by RT-PCR. The primers used for beclin 1 and the internal control glyceraldehyde 3-phosphate dehydrogenase (Sangon Biotech Co., Ltd., Shanghai, China) are indicated in Table I. The reaction was conducted using GeneAmp PCR System 9700 (Applied Biosystems; Thermo Fisher Scientific) and performed at $37^{\circ} \mathrm{C}$ for $15 \mathrm{~min}$, followed by $5 \mathrm{~min}$ at $98^{\circ} \mathrm{C}$, then 35 cycles at $94^{\circ} \mathrm{C}$ for $20 \mathrm{sec}, 53^{\circ} \mathrm{C}$ for $30 \mathrm{sec}$ and $72^{\circ} \mathrm{C}$ for $40 \mathrm{sec}$. PCR products were evaluated on $2 \%$ agarose gels (Thermo Fisher Scientific, Inc.) containing $0.5 \mu \mathrm{g} / \mathrm{ml}$ ethidium bromide (Thermo Fisher Scientific, Inc.), and photographed under an ultraviolet (UV) transilluminator (FR980; Shanghai Furi Science \& Technology Co., Ltd., Shanghai, China). AlphaEaseFC 4.0 software (Genetic Technologies, Inc., Miami, FL, USA) was used to semiquantitatively analyze the relative light intensities of the bands. Triplicate experiments with triplicate samples were performed.

Western blotting. Cells were harvested and cell lysates (30 $\mu \mathrm{g}$ protein/lane) were fractionated by $10 \%$ sodium dodecyl sulfate-polyacrylamide gel electrophoresis (Invitrogen; Thermo Fisher Scientific, Inc.) once quantified. The proteins were electrotransferred onto polyvinylidene fluoride membranes (EMD Millipore, Billerica, MA, USA) and blocked with 5\% nonfat dry milk (BBI Life Sciences Corporation, Shanghai, China) for $1 \mathrm{~h}$ at room temperature. Next, the proteins were detected following incubation for $1.5 \mathrm{~h}$ at room temperature with the following primary antibodies: Anti-beclin 1 (1:5,000; rabbit monoclonal; catalog no. ab51031; Abcam, Cambridge, MA, USA), anti-caspase-3 (1:1,000; rabbit polyclonal; catalog no. 9662; Cell Signaling Technology, Inc., Danvers, MA, USA), anti-Bcl-2 (1:1,000; catalog no. 2872; rabbit polyclonal; Cell Signaling Technology, Inc.), anti-Bcl-2-associated X protein (Bax; 1:1,000; rabbit polyclonal; catalog no. 2772; Cell Signaling Technology, Inc.) and anti- $\beta$-actin, (1:10,000; mouse monoclonal; catalog no. ab6276; Abcam), which served as loading control. Following washes with Tris-buffered saline containing $0.05 \%$ Tween 20 (Sinopharm Chemical Reagent Co., Ltd., Shanghai, China), membranes were incubated with horseradish peroxidase-conjugated goat anti-rabbit (1:1,000; catalog no. ZB-5301) and goat anti-mouse (1:1,000; catalog no. ZB-5305) secondary antibodies (Beijing Zhongshan Golden Bridge Biotechnology Co., Ltd., Beijing, China) for $40 \mathrm{~min}$ at room temperature. The bound antibodies were visualized using an enhanced chemiluminescence reagent (EMD Millipore) and quantified by densitometry using ChemiDoc $^{\mathrm{TM}}$ XRS+ image analyzer (Bio-Rad Laboratories, Inc., Hercules, CA, USA). Densitometric analyses of the bands were adjusted with $\beta$-actin. Triplicate experiments with triplicate samples were performed.

Hoechst 33258 staining. Apoptotic cells were evaluated by observing their morphology using Hoechst 33258 staining (Sigma-Aldrich, St. Louis, MO, USA). Cells of different groups were seeded in 6-well plates at a density of $3 \times 10^{5}$ cells/well, and fixed with $3.7 \%$ paraformaldelyde (Sigma-Aldrich) for $30 \mathrm{~min}$ at room temperature $24 \mathrm{~h}$ later. Next, cells were washed with PBS 3 times for $5 \mathrm{~min}$ each and stained with Hoechst 33258 at $37^{\circ} \mathrm{C}$ for $30 \mathrm{~min}$, prior to be observed under a fluorescence microscope equipped with a UV filter (Eclipse Ti; Nikon Corporation, Tokyo, Japan) at x200 magnification.

\section{3-(4,5-dimethylthiazol-2-yl)-2,5-diphenyltetrazolium bromide} (MTT) assay for the detection of cell proliferation. Following transfection, cells of different groups were collected, seeded in 96-well plates $\left(3 \times 10^{3}\right.$ cells/well) and cultured for 1-7 days. In each group, the medium was removed each day, and the wells were washed with phosphate-buffered saline (Beijing Solarbio Science \& Technology Co., Ltd., Beijing, China). MTT assay was performed by adding $20 \mu \mathrm{l}$ of $5 \mathrm{mg} / \mathrm{ml}$ MTT (Sigma-Aldrich) for $4 \mathrm{~h}$. The absorbance of the solution was then measured at $570 \mathrm{~nm}$ on a ThermoMax microplate reader (Molecular Devices, LLC, Sunnyvale, CA, USA). Cell growth curves of each group were generated according the results obtained. Triplicate experiments with triplicate samples were performed.

Chemosensitivity assay. Cells of different groups at logarithmic phase were collected and seeded in 96-well plates $\left(5 \times 10^{3}\right.$ cells/well). The medium of each group was removed overnight, and the cells were exposed to increasing concentrations of $\operatorname{Taxol}^{\circledR}(0,0.1,1,10,100,500$ and $1,000 \mu \mathrm{g} / \mathrm{ml})$ for $48 \mathrm{~h}$. The results of the above MTT assay were used to calculate the inhibition rate and the half maximal inhibitory concentration $\left(\mathrm{IC}_{50}\right)$ values of Taxol ${ }^{\circledR}$.

Statistical analysis. Data were expressed as the mean \pm standard deviation. Statistical software SPSS version 13.0 (SPSS, Inc., Chicago, IL, USA) was used for the assessment. Student's $t$ test was used to compare the means of two groups and one-way analysis of variance was used for comparing the means of multiple samples. $\mathrm{P}<0.05$ was considered to indicate a statistically significant difference.

\section{Results}

Expression of beclin 1 at the protein and messenger (m)RNA levels. Upon transfection, the protein and mRNA 
Table I. Primer information.

\begin{tabular}{lc}
\hline Gene & \multicolumn{1}{c}{ Primer sequence } \\
\hline Beclin 1 & \\
Forward & 5'-AGGAACTCACAGCTCCATTAC-3' \\
Reverse & 5'-AATGGCTCCTCTCCTGAGTT-3' \\
GAPDH & \\
Forward & 5'-GCACCGTCAAGGCTGAGAA-3' \\
Reverse & 5'-AGGTCCACCACTGACACGTTT-3"
\end{tabular}

GAPDH, glyceraldehyde 3-phosphate dehydrogenase.

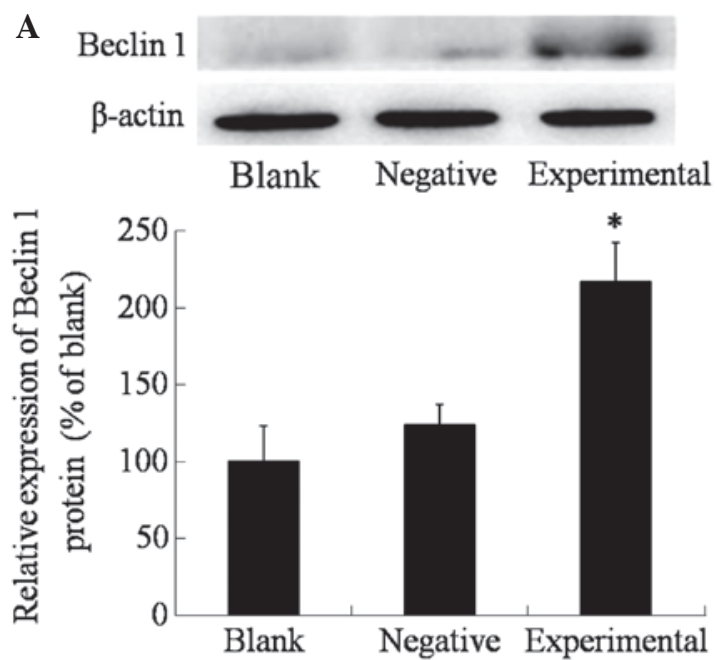

B
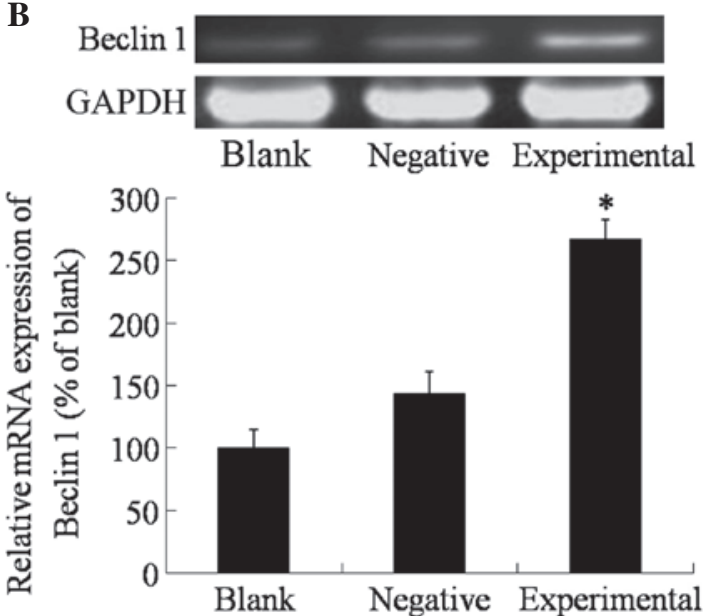

Figure 1. Protein and mRNA expression of beclin 1 in different groups of HeLa cells, as determined by (A) western blotting and (B) reverse transcription-polymerase chain reaction analysis. Bars indicate the relative protein and messenger RNA expression of beclin 1 in different groups of HeLa cells (mean \pm standard deviation; $\mathrm{n}=3 ;{ }^{*} \mathrm{P}<0.05$ ). mRNA, messenger RNA; GAPDH, glyceraldehyde 3-phosphate dehydrogenase.

expression levels of beclin 1 in the different groups were measured using western blotting and RT-PCR, respectively. As shown in Fig. 1, the expression of beclin 1 in the blank and negative control groups was relatively low, and there was



Figure 2. Growth curve was obtained 7 days following transfection. HeLa cells in the blank and negative control groups were in good condition and grew normally, as indicated by their sigmoid growth curve, while the proliferation of HeLa cells transfected with beclin 1 expression vector in the experimental group was significantly inhibited from day 4 post-transfection. ${ }^{*} \mathrm{P}<0.05$. OD, optical density.

no significant differences between the two groups $(\mathrm{P}>0.05)$. However, in the experimental group, the expression of beclin 1 was significantly higher than that in the blank and negative control groups $(\mathrm{P}=0.0364)$, which indicated the success of the transfection with the beclin 1 expression vector.

Effect of beclin 1 expression on the proliferation and apoptosis of HeLa cells. The growth curve of HeLa cells in the different groups was obtained 1-7 days post-transfection. The data indicated that the HeLa cells in the blank and negative control groups were in good condition and grew normally as a sigmoid curve, while the proliferation of HeLa cells transfected with beclin 1 expression vector in the experimental group was significantly inhibited ( $\mathrm{P}=0.0245$; Fig. 2). As shown in Fig. 2, the survival of the cells in the experimental group started to decrease from day 4 post-transfection.

Hoechst 33258 staining for the detection of morphological changes was employed to evaluate the effect of beclin 1 expression on HeLa cells. Following transfection, cells were stained with Hoechst 33258, and apoptotic morphological changes were observed in all the three groups. In the blank and negative control groups, the nuclei of HeLa cells were round and homogeneously stained (Fig. 3) with a low rate of apoptosis, while the cells in the experimental group exhibited evident apoptotic characteristics due to the increase in the levels of beclin 1 , including cell shrinkage, membrane integrity loss or deformation, nuclear fragmentation and chromatin compaction of late apoptotic appearance.

As detected by western blot (Fig. 4), the expression of the apoptotic protein caspase- 3 was elevated in the experimental cells that exhibited high expression levels of beclin $1(\mathrm{P}=0.0163)$, which indicated that beclin 1 may activate the caspase-dependent apoptosis signaling pathway. In addition, the Bcl-2:Bax ratio was decreased in HeLa cells overexpressing beclin 1, which further confirmed that high expression of beclin 1 could activate cell apoptosis.

Effect of beclin 1 expression on the chemosensitivity towards Taxol $^{\circledR}$ of HeLa cells. The effect of beclin 1 expression on 


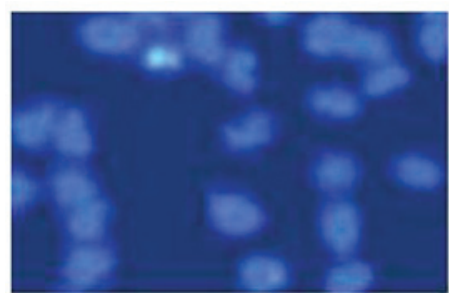

Blank

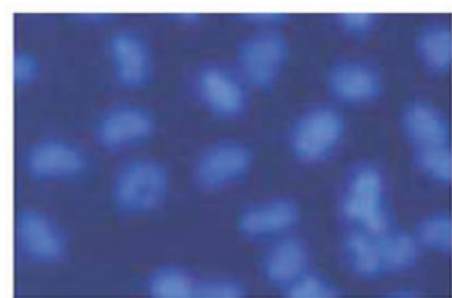

Negative

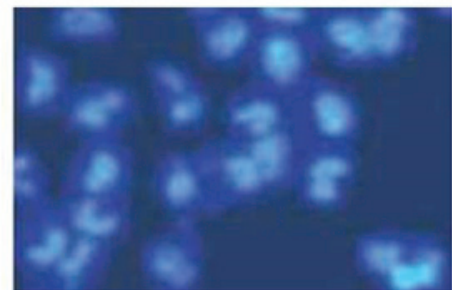

Experimental

Figure 3. Hoechst 33258 staining was used for the detection of morphological changes. In the blank and negative control groups, the nuclei of HeLa cells were round and homogeneously stained with a low rate of apoptosis, while cells in the experimental group exhibited evident apoptotic characteristics, including cell shrinkage, membrane integrity loss or deformation, nuclear fragmentation and chromatin compaction of late apoptotic appearance (magnification, $\mathrm{x} 200$ ).
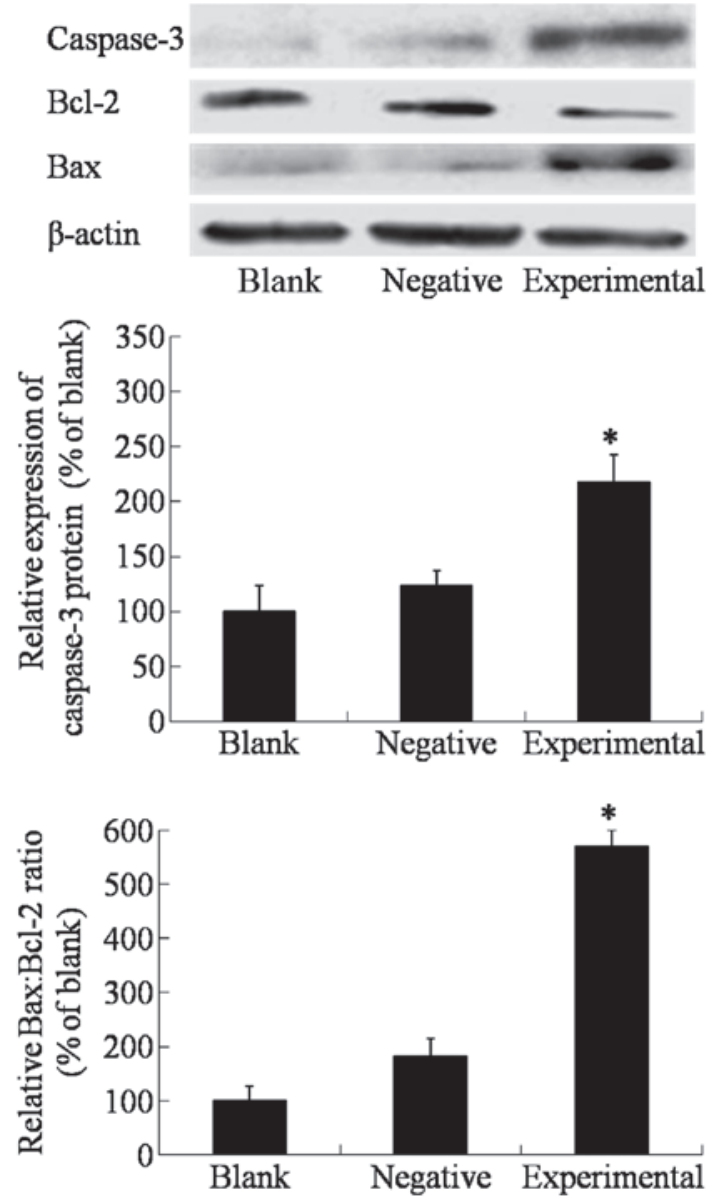

Figure 4. Effects of beclin 1 expression on the levels of cell apoptotic proteins, as measured by western blotting. The protein expression levels of caspase-3 were elevated in the experimental cells that exhibited high expression of beclin 1 , indicating that beclin 1 may activate the caspase-dependent apoptosis signaling pathway in these cells. The ratio of Bcl-2:Bcl-2-associated $\mathrm{X}$ protein was decreased in HeLa cells overexpressing beclin 1, which further confirmed that overexpression of beclin 1 could activate cell apoptosis Bars indicate the relative expression of caspase- 3 and ratio of $\mathrm{Bcl}-2$ : $\mathrm{Bax}$ (mean \pm standard deviation; $\mathrm{n}=3 ;{ }^{*} \mathrm{P}<0.05$ ). Bcl-2, B-cell lymphoma 2; Bax, Bcl-2-associated X protein.

the chemosensitivity of HeLa cells towards Taxol ${ }^{\circledR}$ was evaluated using MTT assay, by measuring the proliferation inhibitory effects of the different concentrations of Taxol ${ }^{\circledR}$ tested in each group. As shown in Fig. 5, the inhibition rate of Taxol ${ }^{\circledR}$ in the experimental group was higher than in the other two groups at the same concentration. $\mathrm{The}^{\mathrm{IC}_{50}}$ values of

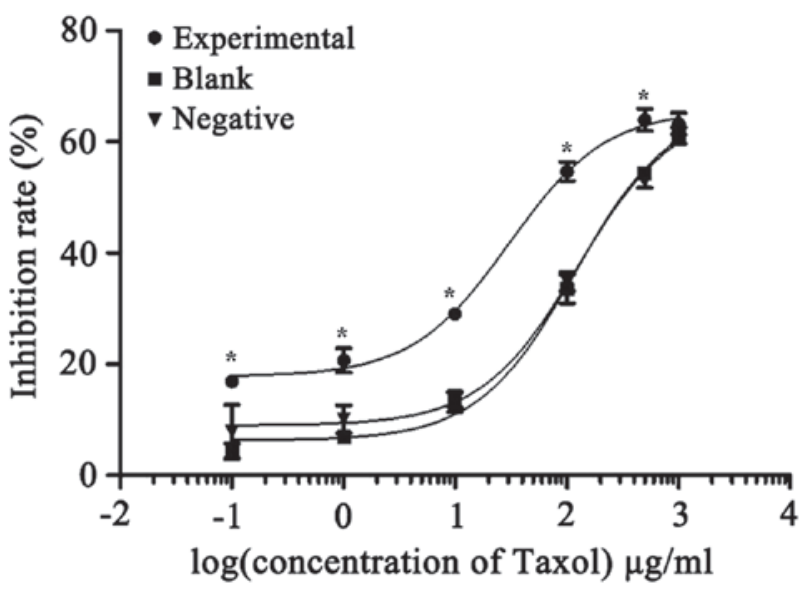

Figure 5. The chemosensitivity towards Taxol ${ }^{\circledR}$ of HeLa cells in each group was detected by 3-(4,5-dimethylthiazol-2-yl)-2,5-diphenyltetrazolium bromide assay. The inhibition rate caused by Taxol ${ }^{\circledR}$ in the experimental group was higher than in the other two groups at the same concentration. ${ }^{*} \mathrm{P}<0.05$.

Taxol ${ }^{\circledR}$ were $30.4,118.0$ and $125.5 \mu \mathrm{g} / \mathrm{ml}$ in the experimental, blank control and negative control groups, respectively. There were no significant differences between the blank and negative control groups $(\mathrm{P}>0.05)$, while in the experimental group, overexpression of beclin 1 significantly reduced the $\mathrm{IC}_{50}$ value of Taxol $^{\circledR}(\mathrm{P}=0.0148)$.

\section{Discussion}

Autophagy is a process of self-digestion of the cytoplasm and organelles of a cell, in which cytoplasmic constituents such as long-lived proteins, protein aggregates and entire organelles are targeted to lysosomes for degradation by means of double-membrane vesicles called autophagosomes (14). Autophagy is an evolutionarily conserved mechanism of cell survival that usually occurs at a low basal level under normal conditions in order to maintain cellular homeostasis (15). Autophagy is highly induced by multiple stimuli, including starvation and metabolic stress (16). Dysfunction of the autophagic pathway has been implicated in various diseases, including cancer, obesity, cardiac disease, neurodegeneration, aging, infection and inflammatory diseases (17-19). However, the role of autophagy in association with cancer and tumorigenesis is complex and highly context-dependent (20). Autophagy may be involved in cell cycle regulation, apoptosis, angiogenesis and other aspects of tumor initiation and progression (21). Previous 
studies have reported that beclin 1 is absent or expressed at very low levels in a wide variety of human tumors, and mutations in the beclin 1 gene have been detected in numerous types of cancer $(2,13,22-25)$. A previous study demonstrated that ectopic expression of beclin 1 in MCF-7 cells activates autophagy, inhibits cellular proliferation and clonogenicity, and suppresses tumorigenesis in mouse xenograft models (26).

There are a number of studies reporting that beclin 1 expression is associated with chemosensitivity $(27,28)$. Beclin 1 may affect the chemosensitivity of cancer cells through several mechanisms. For example, in a previous study on apoptosis induced by etoposide in cervical cancer CaSki cells, overexpression of beclin 1 increased the chemosensitivity and apoptosis rate of CaSki cells $(2,11,29)$. In the present study, a beclin 1 expression vector was constructed and transfected into $\mathrm{HeLa}$ cells in order to obtain HeLa cells with high expression levels of beclin 1 . The results indicated that, following transfection with this beclin 1 expression vector, the expression of beclin 1 was significantly increased at the mRNA and protein levels. Overexpression of beclin 1 in HeLa cells resulted in enhancement of the autophagy process, increased cell apoptosis and inhibition of cell proliferation. By contrast, in the blank and negative control groups, HeLa cells exhibited normal proliferation, with an obvious sigmoid growth curve.

In addition, the chemosensivity of HeLa cells to Taxol ${ }^{\circledR}$ was detected by MTT assay. The results indicated that the $\mathrm{IC}_{50}$ value of Taxol ${ }^{\circledR}$ in normal HeLa cells was $118.0 \mu \mathrm{g} / \mathrm{ml}$, while in HeLa cells transfected with a blank plasmid the $\mathrm{IC}_{50}$ value of Taxol $^{\circledR}$ was $125.5 \mu \mathrm{g} / \mathrm{ml}$, and in HeLa cells transfected with the beclin 1 expression plasmid this value was reduced to $30.4 \mu \mathrm{g} / \mathrm{ml}$. It was also observed that the growth curve of HeLa cells overexpressing beclin 1 was markedly shifted to the left, indicating that the chemotherapy sensitivity of HeLa cells towards Taxol ${ }^{\circledR}$ was markedly increased upon overexpression of beclin 1 .

The autophagic gene beclin 1 regulates apoptosis in different ways in different cells, and a close association exists between autophagy and apoptosis (30). Bcl-2 and Bax are upstream proteins in the mitochondria-mediated apoptotic pathway, and are important regulatory factors of the permeability of the mitochondrial membrane (31). Abnormal signaling of Bcl-2/Bax may affect the release of cytochrome $c$ and the activation of the downstream protease caspase-3, thus further mediating cell survival or cell death (32-34). In the present study, overexpression of beclin 1 could reduce the ratio of $\mathrm{Bcl}-2 / \mathrm{Bax}$ and enhance the expression of caspase-3, indicating that in HeLa cells overexpressing beclin 1, the Bcl-2/Bax and caspase-3 apoptosis signaling pathways were activated.

In conclusion, the present study demonstrated that, following transfection with beclin 1 expression plasmid, the relative mRNA and protein expression levels of beclin 1 were significantly enhanced, cell proliferation was significantly reduced, cell apoptosis rate was increased and the Bcl-2/Bax/caspase-3 apoptosis signaling pathway was activated in HeLa cells. In addition, the $\mathrm{IC}_{50}$ of HeLa cells to paclitaxel was significantly decreased, and its sensitivity to this drug was improved, suggesting that in cervical cancer HeLa cells, beclin 1 may not only regulate the process of autophagy, but it may also regulate cell apoptosis and enhance the sensitivity of cervical cancer cells to paclitaxel. The present results provide novel targets and strategies for improving drug resistance and gene therapy in cervical cancer.

\section{References}

1. Jia Y, Li S, Yang R, Zhou H, Xiang Q, Hu T, Zhang Q, Chen Z, Ma D and Feng L: Knowledge about cervical cancer and barriers of screening program among women in Wufeng County, a high-incidence region of cervical cancer in China. PLoS One 8: e67005, 2013

2. Sun Y, Liu JH, Sui YX, Jin L, Yang Y, Lin SM and Shi H: Beclin1 overexpression inhibitis proliferation, invasion and migration of CaSki cervical cancer cells. Asian Pac J Cancer Prev 12: 1269-1273, 2011.

3. Zhang SK, Kang LN, Chang IJ, Zhao FH, Hu SY, Chen W, Shi JF, Zhang X, Pan QJ, Li SM and Qiao YL: The natural history of cervical cancer in Chinese women: Results from an 11-year follow-up study in China using a multistate model. Cancer Epidemiol Biomarkers Prev 23: 1298-1305, 2014.

4. Deng Q, Wang Z, Wang L, Zhang L, Xiang X, Wang Z and Chong T: Lower mRNA and protein expression levels of LC3 and Beclin1, markers of autophagy, were correlated with progression of renal clear cell carcinoma. Jpn J Clin Oncol 43: 1261-1268, 2013.

5. Wang ZH, Li L, Peng ZL and Duan ZL: Effect of autophagy gene Beclin 1 on the growth of cervical cancer HeLa cells in vitro and in vivo. Zhonghua Zhong Liu Za Zhi 33: 804-809, 2011 (In Chinese).

6. Denton D, Nicolson S and Kumar S: Cell death by autophagy: Facts and apparent artefacts. Cell Death Differ 19: 87-95, 2012.

7. Liang XH, Kleeman LK, Jiang HH, Gordon G, Goldman JE, Berry G, Herman B and Levine B: Protection against fatal Sindbis virus encephalitis by beclin, a novel Bcl-2-interacting protein. J Virol 72: 8586-8596, 1998.

8. Oberstein A, Jeffrey PD and Shi Y: Crystal structure of the Bcl-XL-Beclin 1 peptide complex: Beclin 1 is a novel BH3-only protein. J Biol Chem 282: 13123-13132, 2007.

9. Liu B, Bao JK, Yang JM and Cheng Y: Targeting autophagic pathways for cancer drug discovery. Chin J Cancer 32: 113-20, 2013.

10. Meijer AJ and Codogno P: Regulation and role of autophagy in mammalian cells. Int J Biochem Cell Biol 36: 2445-2462, 2004.

11. Sun Y, Liu JH, Jin L, Lin SM, Yang Y, Sui YX and Shi H: Over-expression of the Beclin1 gene upregulates chemosensitivity to anti-cancer drugs by enhancing therapy-induced apoptosis in cervix squamous carcinoma CaSki cells. Cancer Lett 294: 204-210, 2010.

12. Jin S and White E: Role of autophagy in cancer: Management of metabolic stress. Autophagy 3: 28-31, 2007.

13. Shin JY, Hong SH, Kang B, Minai-Tehrani A and Cho MH: Overexpression of beclin1 induced autophagy and apoptosis in lungs of K-rasLA1 mice. Lung Cancer 81: 362-370, 2013.

14. He C and Klionsky DJ: Regulation mechanisms and signaling pathways of autophagy. Annu Rev Genet 43: 67-93, 2009.

15. Levine B and Kroemer G: Autophagy in the pathogenesis of disease. Cell 132: 27-42, 2008.

16. Kroemer G, Mariño G and Levine B: Autophagy and the integrated stress response. Mol Cell 40: 280-293, 2010.

17. Cheng Y, Ren X, Hait WN and Yang JM: Therapeutic targeting of autophagy in disease: Biology and pharmacology. Pharmacol Rev 65: 1162-1197, 2013.

18. Kimmelman AC: The dynamic nature of autophagy in cancer. Genes Dev 25: 1999-2010, 2011.

19. Ravikumar B, Sarkar S, Davies JE, Futter M, Garcia-Arencibia M, Green-Thompson ZW, Jimenez-Sanchez M, Korolchuk VI, Lichtenberg M, Luo S, et al: Regulation of mammalian autophagy in physiology and pathophysiology. Physiol Rev 90: 1383-1435, 2010.

20. Ambjørn M, Ejlerskov P, Liu Y, Lees $M$, Jäättelä $M$ and Issazadeh-Navikas S: IFNB1/interferon- $\beta$-induced autophagy in MCF-7 breast cancer cells counteracts its proapoptotic function. Autophagy 9: 287-302, 2013.

21. Filippi-Chiela EC, Villodre ES, Zamin LL and Lenz G: Autophagy interplay with apoptosis and cell cycle regulation in the growth inhibiting effect of resveratrol in glioma cells. PLoS One 6: e20849, 2011.

22. Wirawan E, Lippens S, Vanden Berghe T, Romagnoli A, Fimia GM, Piacentini $M$ and Vandenabeele P: Beclin1: A role in membrane dynamics and beyond. Autophagy 8: 6-17, 2012. 
23. Li X, Yan J, Wang L, Xiao F, Yang Y, Guo X and Wang H: Beclin inhibition promotes autophagy and decreases gemcitabine-induced apoptosis in Miapaca2 pancreatic cancer cells. Cancer Cell Int 13: 26, 2013.

24. Zhao J, Wang ML, Li Z, Gao DM, Cai Y, Chang J and Wang SP: Interferon-alpha-2b induces autophagy in hepatocellular carcinoma cells through Beclin1 pathway. Cancer Biol Med 11: 64-68, 2014.

25. Duan ZL, Peng ZL, Wang ZH and Yan NH: Correlation of autophagy gene Beclin1 to tumorigenesis and development of epithelial ovarian cancer. Ai Zheng 26: 258-263, 2007 (In Chinese).

26. Liang XH, Jackson S, Seaman M, Brown K, Kempkes B Hibshoosh $\mathrm{H}$ and Levine B: Induction of autophagy and inhibition of tumorigenesis by beclin 1. Nature 402: 672-676, 1999.

27. Wu XY, Chen J, Cao QH, Dong M, Lin Q, Fan XJ, Xia Q, Chen ZH, Liu Q and Wan XB: Beclin 1 activation enhances chemosensitivity and predicts a favorable outcome for primary duodenal adenocarcinoma. Tumour Biol 34: 713-722, 2013.

28. Wang TT, Cao QH, Chen MY, Xia Q, Fan XJ, Ma XK, Lin Q, Jia CC, Dong M, Ruan DY, et al: Beclin 1 deficiency correlated with lymph node metastasis, predicts a distinct outcome in intrahepatic and extrahepatic cholangiocarcinoma. PLoS One 8: e80317, 2013.
29. Sun Y, Jin L, Liu J, Lin S, Yang Y, Sui Y and Shi H: Effect of autophagy on paclitaxel-induced CaSki cell death. Zhong Nan Da Xue Xue Bao Yi Xue Ban 35: 557-565, 2010.

30. Niu TK, Cheng Y, Ren X and Yang JM: Interaction of Beclin 1 with survivin regulates sensitivity of human glioma cells to TRAIL-induced apoptosis. FEBS Lett 584: 3519-3524, 2010.

31. Lindsay J, Esposti MD and Gilmore AP: Bcl-2 proteins and mitochondria - specificity in membrane targeting for death. Biochim Biophys Acta 1813: 532-539, 2011.

32. Du P, Cao H, Wu HR, Zhu BS, Wang HW, Gu CW, Xing CG and Chen W: Blocking Bcl-2 leads to autophagy activation and cell death of the HEPG2 liver cancer cell line. Asian Pac J Cancer Prev 14: 5849-5854, 2013.

33. Yao Q, Chen J, Lv Y, Wang T, Zhang J, Fan J and Wang L: The significance of expression of autophagy-related gene Beclin, Bcl-2, and Bax in breast cancer tissues. Tumour Biol 32: 1163-1171, 2011

34. Wang W, Fan H, Zhou Y, Duan P, Zhao G and Wu G Knockdown of autophagy-related gene Beclin1 promotes cell growth and inhibits apoptosis in the A549 human lung cancer cell line. Mol Med Rep 7: 1501-1505, 2013. 